SCIENTIFIC LETTER

\title{
The natural history of left ventricular systolic function in Anderson-Fabry disease
}

\author{
J S Shah, P Lee, D Hughes, R Thaman, B Sachdev, D Pellerin, A Mehta, P M Elliott
}

Heart 2005;91:533-534. doi: 10.1136/hrt.2004.035584

A nderson-Fabry disease (AFD), an X linked lysosomal storage disorder, results in glycoshingolipid deposition in multiple organ systems, including the heart. Recognised cardiac manifestations include conduction disease, valvar thickening, and left ventricular hypertrophy (LVH). ${ }^{1}$ Recent studies have shown that enzyme replacement therapy (ERT) reduces left ventricular (LV) mass in patients with AFD. ${ }^{2}$ It remains uncertain, however, whether LVH is a clinically relevant surrogate marker of disease severity.

Weidemann and colleagues ${ }^{2}$ have shown that tissue Doppler derived strain rate improves during treatment with ERT, suggesting that contractile function is reversibly impaired in AFD cardiomyopathy. To determine the importance of systolic performance in the natural history of AFD we performed a retrospective analysis of an untreated cohort of patients followed for at least one year.

Seventy five patients with AFD were evaluated at the Heart Hospital, London between 1 January 1993 and 1 December 2003. Diagnosis of AFD was based on low plasma $\alpha$ galactosidase A $(\alpha-\mathrm{Gal})$ concentrations and DNA mutational analysis. The mean (SD) follow up from diagnosis of AFD was 5.8 (4.8) years. Twenty four patients had been followed up for more than one year; 12 were receiving ERT at the time of evaluation. The 12 untreated patients (nine male patients, three female patients, mean age 54.5 (12.2) years, range 4282 years) formed the study cohort; all had at least two evaluations separated by one year or more. All patients underwent clinical examination, supine ECG, echocardiography, and 24 hour ambulatory ECG monitoring.

Plasma $\alpha$-Gal activity was measured with the fluorogenic substrate 4-methylumbelliferyl- $\alpha$-D-galactopyranoside (Sigma), with $\mathrm{N}$-acetyl-D-galactosamine (Nacalai Tesque) used as an inhibitor of $\alpha$-N-acetylgalactosaminidase. A plasma $\alpha$-Gal activity of $\leqslant 1.2 \mathrm{nmol} / \mathrm{h} / \mathrm{ml}$ was considered diagnostic of AFD.

The following parameters, using a GE System V echocardiograph, were measured: end diastolic LV cavity diameter (LVed), diastolic interventricular septal thickness (IVS), diastolic posterior wall thickness (PW), and end systolic cavity diameter (LVes). Maximum LV wall thickness was defined as the greatest thickness in any single segment. Relative wall thickness (RWT) was calculated as (IVS + PW)/ LVed, at mitral valve level. LV remodelling or LVH was defined as a RWT $>0.45 .^{3} \mathrm{LV}$ mass was calculated by the Devereux modified cube formula and indexed to body surface area, LV mass index (LVMI). LV geometry was classified as normal (normal LVMI and normal RWT), concentric remodelling (normal LVMI and increased RWT), eccentric LVH (increased LVMI and normal RWT), and concentric LVH (increased LVMI and increased RWT). Fractional shortening (FS) $([$ LVed - LVes/LVed] $\times 100)$ was used to measure systolic performance.

The $\chi^{2}$ test and the two tailed paired Student's $t$ test were used where appropriate. All values are expressed as mean (SD). Significance was defined as $p \leqslant 0.05$.

\section{RESULTS}

Mean plasma $\alpha$-Gal concentration was 1.3 (1.5) nmol/h/ml. Four patients (three females, one male) had concentrations $>1.2 \mathrm{nmol} / \mathrm{h} / \mathrm{ml}$ but had disease causing mutations. The mean time between the echocardiograms was 3.3 (2.7) years (range 1-9 years).

The baseline P-R interval was 141.5 (22.3) ms; baseline QRS duration was 112.7 (25.0) ms. During follow up, no change in P-R interval was observed. There was an increase in the QRS duration (mean $4.2 \mathrm{~ms}$, 95\% confidence interval (CI) 4.0 to $24.4 \mathrm{~ms} ; \mathrm{p}=0.012$ ). Patients with pacemakers were excluded from this analysis.

Eight patients $(66.7 \%)$ had concentric LVH and three $(25 \%)$ had concentric remodelling at baseline. A single (female) patient had normal LV geometry at baseline. Of the three patients with concentric remodelling, one progressed to concentric LVH, one to normal geometry, and one had no change. Of the eight patients with concentric LVH, one progressed to eccentric LVH and one to concentric remodelling. Maximal LV wall thickness was 19.1 (6.0) mm at baseline with an LVMI of $177.8(66.2) \mathrm{g} / \mathrm{m}^{2}$. There was no increase in the LVMI at follow up (184.9 (63.8) g/m² $\mathrm{p}=0.4)$.

Baseline LVed, LVes, and FS were 45.6 (4.4) mm, 26.0 (4.4) $\mathrm{mm}$, and $42.9(6.5) \%$, respectively. During the observation period, LVes increased (5 (6.9) $\mathrm{mm}, 95 \%$ CI 0.2 to $9.6 \mathrm{~mm} ; \mathrm{p}=0.038)$, and FS decreased $(6.1(8.7) \%, 95 \% \mathrm{CI}$ $0.3 \%$ to $11.9 \% ; p=0.042$ ) (fig 1 ). There was a trend towards an increasing LVed $(2.9(5.4) \mathrm{mm}, 95 \%$ CI -0.5 to $6.35 \mathrm{~mm}$; $\mathrm{p}=0.088$ ). The rate of change in the FS was $2.7 \%$ per year. Three patients demonstrated a reduction in LVes during follow up. One patient (45 year old female) had a $6 \mathrm{~mm}$ reduction in LVes, an $11 \%$ increase in the $\mathrm{FS}$, a $5 \mathrm{~mm}$ increase in LV wall thickness, and changed from normal LV geometry to concentric LVH. The other two patients had $2 \mathrm{~mm}$ reductions in LVes. These reductions were associated with a $1 \%$ reduction in FS in one patient and an increase of $4 \%$ in the other.

During follow up, two (17\%) patients had non-sustained ventricular tachycardia; one $(8 \%)$ received an implantable cardiac defibrillator. Four $(33.3 \%)$ patients required permanent pacemakers: two for symptomatic bradycardia, one for congestive heart failure (biventricular device), and one patient for complete heart block following alcohol septal ablation. Two other patients progressed to congestive heart failure.

Abbreviations: $\alpha$-Gal, $\alpha$-galactosidase A; AFD, Anderson-Fabry disease; ERT, enzyme replacement therapy; FS, fractional shortening; IVS, interventricular septal thickness; LV, left ventricular; LVed, end diastolic left ventricular cavity diameter; LVes, end systolic left ventricular cavity diameter; LVH, left ventricular hypertrophy; LVMI, left ventricular mass index; PW, diastolic posterior wall thickness; RWT, relative wall thickness 


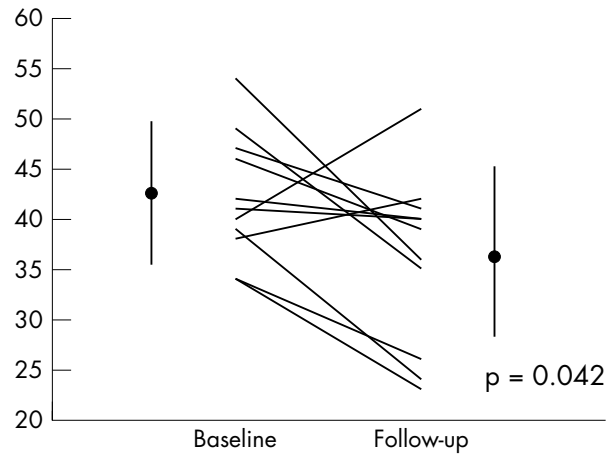

Figure 1 Fractional shortening (FS). Error bars represent mean (SD) for baseline and follow up respectively for FS (\%); 42.9 (6.5), 36.1 (8.6).

\section{DISCUSSION}

This study demonstrates that LV systolic function progressively deteriorates in untreated patients with AFD. Histologically, AFD is characterised by myocyte vacuolation and intralysosomal inclusions on electron microscopy. ${ }^{4}$ Moreover, substrate accumulation accounts for only $1 \%$ of the increased LV mass seen in AFD patients. ${ }^{4}$ We have recently shown that patients with AFD have areas of interstitial expansion on cardiac magnetic resonance imaging, ${ }^{5}$ suggesting that progressive fibrosis may contribute to the reduction in systolic performance.

This study uses a relatively simple assessment of systolic function. However, FS is used widely in routine clinical practice and is frequently accepted as an index of systolic function in multi-centre studies. The study is also limited by the size of the cohort and the fact that patients had severe cardiac disease. These findings may, therefore, reflect a late phase in the natural history of AFD cardiomyopathy.

In conclusion, this study suggests that systolic performance should be monitored in patients with AFD, and that systolic function may be a useful surrogate marker of response to ERT.

\section{ACKNOWLEDGEMENTS}

Dr J S Shah and Dr D Hughes are supported by educational grants from Transkaryotic Therapies (TKT-5S)

\section{Authors' affiliations}

J S Shah, R Thaman, B Sachdev, D Pellerin, P M Elliott, The Heart Hospital, University College London, UK

P Lee, Charles Dent Metabolic Unit, National Hospital for Neurology and Neurosurgery, London, UK

D Hughes, A Mehta, Lysosomal Storage Disorders Unit, Royal Free Hospital, London, UK

Correspondence to: Dr Perry M Elliott, The Heart Hospital, 16-18 Westmoreland Street, London WIG 8PH, UK; perry.elliott@uclh.org

Accepted 27 July 2004

\section{REFERENCES}

1 Desnick RJ, loannou YA, Eng CM. a-Galactosidase A deficiency: Fabry disease. In: Scriver CR, Beaudet AL, Sly WS, Valle D, eds. The metabolic and molecular bases of inherited disease, 8th ed. New York: McGraw-Hill, 2001:3733-74.

2 Weidemann F, Breunig F, Beer M, et al. Improvement of cardiac function during enzyme replacement therapy in patients with Fabry disease: a prospective strain rate imaging study. Circulation 2003;108:1299-301.
3 Devereux RB, Alonso DR, Lutas EM, et al. Echocardiographic assessment of left ventricular hypertrophy: comparison to necropsy findings. Am J Cardiol 1986;57:450-8.

4 Elleder M, Bradova V, Smid F, et al. Cardiocyte storage and hypertrophy as a sole manifestation of Fabry's disease. Report on a case simulating hypertrophic non-obstructive cardiomyopathy. Virchows Arch A Pathol Anat Histopathol 1990;417:449-55.

5 Moon JC, Sachdev B, Elkington AG, et al. Gadolinium enhanced cardiovascular magnetic resonance in Anderson-Fabry disease. Evidence for a disease specific abnormality of the myocardial interstitium. Eur Heart $J$ 2003;24:2151-5

\section{WEB TOP 10}

www.heartinl.com

These articles scored the most hits on Heart's website during January 2005

1 Tissue Doppler, strain, and strain rate echocardiography for the assessment of left and right systolic ventricular function

$D$ Pellerin, $R$ Sharma, $P$ Elliott, C Veyrat

November 2003;89(suppl III):iii9-17. (Supplement)

2 Investigation and management of chest pain

$K$ F Fox

January 2005;91:105-10. (Education in Heart)

3 Management of acute coronary syndromes: an update $K$ A A Fox

June 2004;90:698-706. (Education in Heart)

4 Catheter ablation for atrial fibrillation

$P$ Jais, $P$ Sanders, L F Hsu, M Hocini, $M$ Haissaguerre January 2005;91:7-9. (Editorial)

5 Joint British recommendations on prevention of coronary heart disease in clinical practice

December 1998;80:1-29.

6 Should ablation be the first line treatment for supraventricular arrhythmias?

F G Cosio

January 2005;91:5-6. (Editorial)

7 Clinical assessment of myocardial hibernation

A F L Schinkel, J J Bax, D Poldermans

January 2005;91:111-17. (Education in Heart)

8 Left ventricular hypertrophy in hypertension: its arrhythmogenic potential

$T$ Kahan, L Bergfeldt

February 2005;91:250-6. (Education in Heart)

9 Management of hypertension before, during, and after pregnancy

$P R$ James, C Nelson-Piercy

December 2004;90:1499-504. (Education in Heart)

10 The French paradox: lessons for other countries $J$ Ferrieres

January 2004;90:107-11. (Education in Heart)

Visit the Heart website for hyperlinks to these articles, by clicking on "Top 10 papers"

www.heartinl.com 